\title{
Regulaciones públicas y explotación de renta de suelo: el boom inmobiliario de Ñuñoa, Santiago, 2000-2010
}

\section{Public regulations and ground rent exploitation: the real estate boom in Ñuñoa, Santiago, 2000-2010}

\author{
Ernesto López-Morales* \\ Daniel Meza-Corvalán**
}

\begin{abstract}
This paper presents an analysis of the urban renewal process of the Irarrazaval poniente area, in the Nuñoa municipality, Santiago, Chile, which during the past decade witnessed an intensive market-led real estate housing production, aimed at middle-upper income strata. Results show the active role played by state-led neoliberal policies, deployed at local-level, which aim to define the highest land use to be exclusively exploited by real estate firms. It is also shown the increasingly differential ground rent levels either captured by realtors and owner-residents, which means gentrification for a smaller number of residents.
\end{abstract}

Keywords: urban renewal, gentrification, ground rent.

\section{Resumen}

Esta investigación presenta un análisis de la renovación urbana del área de Irarrázaval poniente, comuna de Nunnoa, Santiago, que durante la década pasada experimentó una intensificación de producción privada residencial en altura orientada a segmentos medio-altos. Los resultados muestran el activo rol que juegan, a nivel local, las regulaciones estatales neoliberales en Chile para fijar el más intenso uso del suelo a explotarse exclusivamente por empresas inmobiliarias. Se muestra además el diferencial creciente de rentas de suelo capturadas entre empresas y residentes propietarios tradicionales, lo que implica gentrificación para un segmento minoritario de éstos.

Palabras clave: renovación urbana, gentrificación, renta de suelo.

*Universidad de Chile. Correo-e: elopez@uchilefau.cl

** Universidad de Chile. Correo-e: dmeza@uchilefau.cl 


\section{Introducción}

Los procesos de reestructuración urbana en zonas centrales consolidadas que se experimentan en diversas metrópolis mundiales son una constante de la globalización económica imperante. Tales procesos, generalmente, se intensifican en las áreas metropolitanas que ofrecen mayor potencial de retorno económico, así como mayor grado de flexibilidad de localización y escala de la inversión inmobiliaria, de origen financiero global y local (Smith, 2002). En los países de neoliberalismo avanzado, los gobiernos nacionales, metropolitanos y locales operan asociadamente con productores inmobiliarios, mientras que la estructura estatal local municipal se remodela para parecerse cada vez más a la del sector privado (Weber, 2002).

Asimismo, en los países del norte global este proceso fue parte fundamental de los ajustes asociados a la desindustrialización económica a partir de la década de los ochenta (Hamnett y Whitelegg, 2007), ajustes impulsados por gobiernos locales con tinte pro-empresarial, generalmente dependientes de asociaciones público-privadas centradas en el desarrollo económico especulativo (Harvey, 1989). Actualmente estas estrategias de acumulación capitalista son adoptadas cada vez más por gobiernos locales en todo el mundo, desde aquellos de corte neoliberal hasta, paradójicamente, los más progresistas (Hackworth, 2007; Peck y Tickell, 2002).

Por ejemplo, son ya emblemáticos los casos de implementación de incentivos financieros, impositivos y de condiciones de constructibilidad de suelo, para atraer negocios inmobiliarios, mejorar el ambiente de inversión y capturar mayor cantidad de insumos del sector privado en el desarrollo de la propiedad urbana, como apalancamiento importante para el crecimiento del PIв nacional y regional (Molotch, 1993; Shin, 2009). Esto ocurre en paralelo, con diversas particularidades, en enclaves urbanos de distinta localización y naturaleza global.

Las administraciones locales urbanas en general absorben riesgos políticos con el fin de fomentar la participación del sector privado y asegurar retornos más sustanciales, generando las condiciones regulatorias necesarias para reducir al máximo posible la incertidumbre asociada a la volatilidad del capital financiero. Usualmente, los gobiernos locales, y no el sector privado, son el blanco visible predilecto de las críticas del activismo urbano en contra de los procesos de gentrificación y explotación del suelo con objetivos rentabilizadores.

Esto supera la creencia, a estas alturas mitológica, del rol del Estado neoliberal como un factor débilmente regulador del mercado, cuando éste es más bien un ente público que monopoliza la toma de decisiones y se ajusta a las dinámicas y demandas cíclicas y anti-cíclicas de la megainver- 
sión privada (Mattos, 2007, 2010) y se responsabiliza institucionalmente al momento de absorber las responsabilidades sociales y políticas de tales ajustes.

En Chile, existe también una legislación impositiva blanda que apenas grava las ganancias del desarrollo inmobiliario y que no cuenta con un sistema de captura de plusvalía de suelo que asegure el retorno parcial de tales ganancias a las arcas públicas, ganancias generadas por una renta de suelo aumentada por efecto de infraestructuras y servicios de financiamiento público (Sandroni, 2011; Smolka, 2013). Es en este contexto que los procesos de reestructuración urbana en las principales ciudades chilenas se intensificaron notablemente tras la recuperación nacional de la crisis asiática en 2002.

Fue entonces cuando el tejido urbano consolidado de parte importante del área central y anillo pericentral (que bordea el centro metropolitano) de Santiago se recompuso, fruto de una mayor fluidez y movilidad de un mercado cada vez más dinámico. Esto, hasta el 2009, cuando las empresas comenzaron a sufrir nuevamente una disminución de demanda y financiamiento bancario privado a partir de la crisis global de origen especulativo inmobiliario del año anterior en los EEUU y Reino Unido, con una recuperación que, en el caso chileno, llegaría dos años después.

Por otra parte, en Chile hay una tendencia cada vez más preponderante de los mercados inmobiliarios hacia el desarrollo en el interior de las ciudades grandes en modalidad de renovación urbana en altura. En el caso de Santiago, entre 2000 y 2010, para las 11 comunas (municipios) central y pericentrales, el crecimiento en permisos de edificación para vivienda (mayormente edificios de apartamentos orientados a segmentos medios) aumentó desde 2,580 a 31,500 unidades de vivienda anuales, lo que refleja un espectacular aumento de 1,120 por ciento. ${ }^{1}$

Medido en término de participación a nivel de la región de Santiago, los metros cuadrados producidos en renovación residencial en las comunas del inner city santiaguino se incrementan desde un mero $7.5 \%$ en 2000, hasta un preponderante $44 \%$ en 2010 . En abierto contraste, la construcción de vivienda en la periferia, tradicionalmente expansiva y el cono centro-oriente de alta renta (es decir, las cinco comunas del barrio alto), decrecieron en conjunto de $81 \%$ a $38.5 \%$ durante el mismo lapso.

Complementariamente, el resto de la producción se localizó en comunas satelitales de incorporación reciente en el sistema metropolitano, que incrementaron su producción residencial de $11 \%$ a $17.6 \%$ del total regional, correspondiente mayormente a producción de vivienda social (Hidalgo et al., 2007). Se trata de una reversión profunda de las lógicas

${ }^{1}$ Veáse www.observatoriourbano.cl 
tradicionalmente centrifugas de localización espacial de la inversión inmobiliaria en la región.

En Santiago, del 2006 en adelante, la superficie autorizada para construcción de apartamentos pasa a ocupar 57\% del total de producción de vivienda autorizada en la región Metropolitana (71,794 unidades de un total de 163,236 autorizadas para ese año). Esto habla de un creciente dominio de la modalidad de producción de vivienda económica vía condominio privado en altura, localizada fundamentalmente en las comunas pericentrales, que cuentan con mayor accesibilidad y ofertas de empleo, así como cercanía a servicios y bienes públicos tales como educación, salud municipal y áreas verdes.

En otras palabras, actualmente y por lejos, la renovación urbana es la forma cuantitativamente predominante del boom inmobiliario de la región de Santiago, que verticaliza además su estructura física e imagen de forma similar a la experimentada por megalópolis como la ciudad de México o Sao Paulo desde ya hace varias décadas.

Este artículo se focaliza en el desarrollo de la comuna (municipio) de Nunnoa ${ }^{2}$ entre 2000 y 2010, municipio componente del pericentro o inner city de Santiago (Mapa I). Nunnoa es originalmente un espacio residencial de densidad media-baja consolidado durante el proceso de expansión de barrios de clase media emergente en la segunda mitad de siglo Xx. En las últimas décadas, la comuna ha desarrollado un proceso de renovación de sus edificaciones, es el segundo municipio con mayor volumen de construcción y venta de unidades residenciales de renovación, sólo después de la comuna de Santiago.

Como estudio de caso, su selección responde a varios motivos: primero, Nuñoa ejemplifica la tendencia expansiva de la renovación en altura de Santiago, con un boom inmobiliario residencial intensificado entre 2005 y 2008 y un enfriamiento al 2009; segundo, se observa allí un rol activo del municipio en la elaboración y modificaciones sucesivas de instrumentos de planificación territorial, principalmente el Plan Regulador Comunal de Nuñoa (PRC); tercero, existe un activismo vecinal organizado a favor de la preservación del patrimonio urbano construido y contra la sobreexplotación privada del suelo.

En rigor, la creciente preocupación de la academia y del activismo urbano $^{3}$ por el boom inmobiliario en las zonas urbanas consolidadas de Santiago, así como la gestión municipal que lo sustenta (Janoschka et al. 2014; Janoschka y Casgrain, 2011; Mlynarz, 2007; Aguirre y León, 2007; Núñez, 2006) dan cuenta de los intensos impactos que está generando el

\footnotetext{
${ }^{2}$ Una de las primeras conformaciones municipales del país, que data desde la Ley de Comuna Autónoma de 1891 (Ramón, 2000).

${ }^{3}$ Veáse dos casos en http://www.elsitiodeyungay.cl y http://mplchile.cl
} 


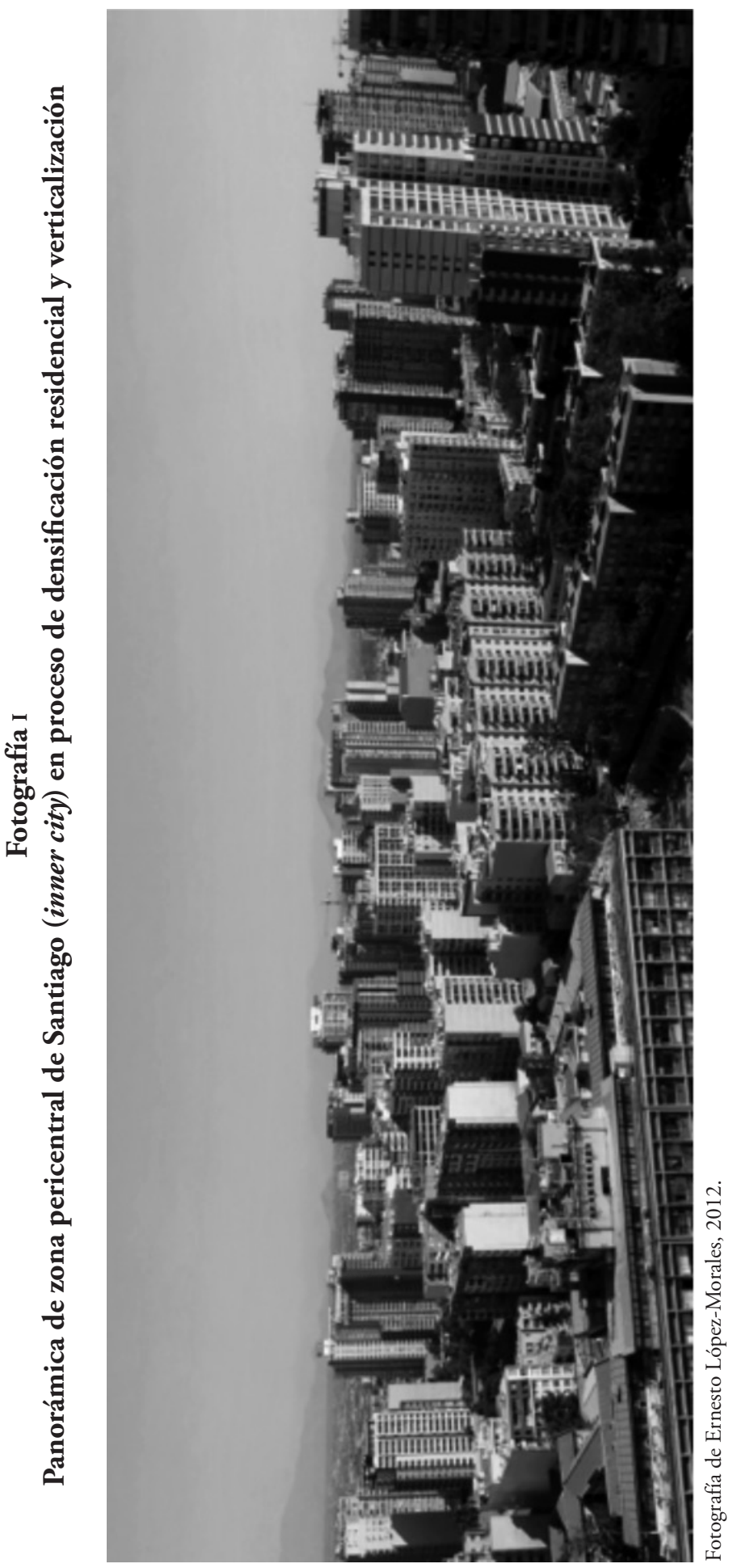


mercado de renovación urbana sobre el patrimonio construido, el medioambiente, y las economías locales de suelo y vivienda.

Cuarto, del conjunto de las 11 comunas del inner city de Santiago (mapa I), Nuñoa es la que presenta, en promedio, el mayor nivel socioeconómico en sus estratos residenciales originales, así como los más altos niveles históricos de precio de suelo. Al tratarse de un proceso explosivo de escala e intensidad sin precedentes en la ciudad, algunos autores relacionan ciertos atributos del reciente boom inmobiliario de Núñoa con un proceso de gentrificación (Contreras, 2011; Schlack y Turnbull, 2015; Inzulza-Contardo, 2012).

Sin embargo, la evidencia entregada por este trabajo indica que tal proceso podría no estarse dando aquí con demasiada incidencia, ya que no se verifican procesos mayoritarios de desplazamiento de residentes tradicionales en condiciones económicamente desventajosas (en este caso, por desposesión de la renta de suelo que poseen), como condición necesaria para la existencia de un proceso cabal de gentrificación (LópezMorales, 2011, 2013a, 2013b).

Se debe considerar que la gentrificación es de por sí un reemplazo de usuarios tradicionales residentes, desde un determinado sector en proceso de cambio, desplazados por usuarios nuevos, de mayor ingreso económico y que, generalmente, ostentan mayor influencia en las esferas del poder político (Smith, 2013; Clark, 2005). Es decir, una corroboración de la existencia de gentrificación en un lugar determinado, necesariamente corrobora la existencia de una baja captura de renta de suelo por parte de los propietarios residentes, quienes venden su suelo al mercado inmobiliario con un valor que los inhabilite a permanecer en dicho lugar.

El valor de uso de la renta de suelo, su variación, y la forma en que éste es desposeído de quienes tradicionalmente lo capitalizan son los rasgos más gravitantes de la gentrificación según el modelo explicativo estructural marxista. Con base en esta definición el presente artículo realiza un análisis comparativo detallado de dos tipos de ganancia por suelo, es decir, una renta de suelo socialmente capitalizada, y otra potencial, según las clasificaciones realizadas por Smith $(1979,1982)$ y Clark $(1988,1995,2005)$ para estudios de suelo urbano y gentrificación.

La renta capitalizada por un propietario de suelo implica que ese agente económico tiene la capacidad de negociar con ese bien, arrendarlo o venderlo en condiciones determinadas y transformarlo en ganancia o capital por medio de la venta de su propiedad, en las condiciones de mercado que le son permitidas por el marco legal y económico dominante.

En una ciudad como Santiago, donde cerca de $70 \%$ de sus residentes poseen formalmente el suelo sobre el que habitan, la renta de suelo urbano es un factor fundamental de desarrollo económico y social de los hogares, 


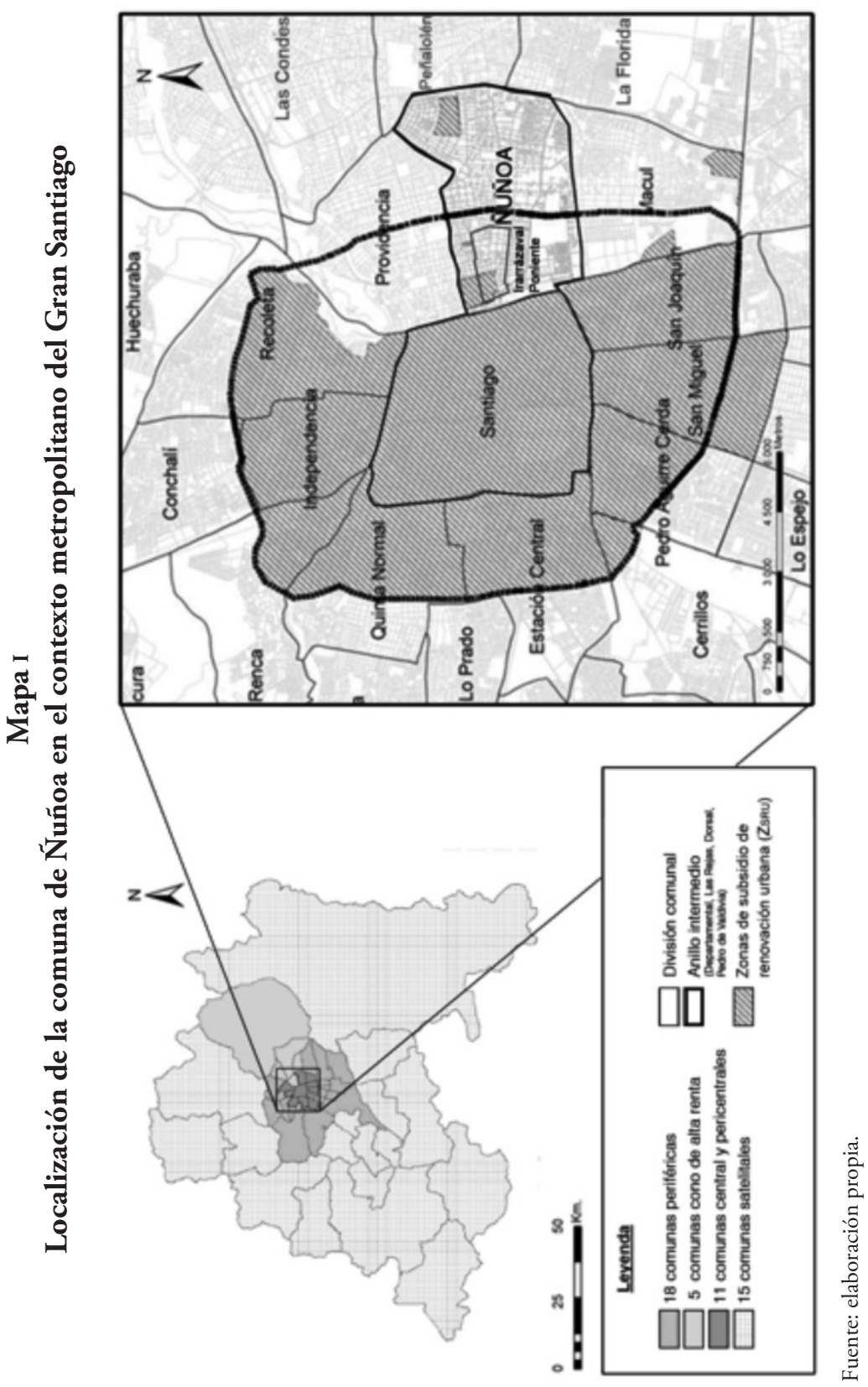


así como un asegurador gravitante de su permanencia en un sector determinado en transformación de condiciones más o menos ventajosas ante una eventual movilidad residencial.

Sin embargo, hay una segunda renta de tipo potencial, mucho más alta y de carácter monopólico, que tiene que ver con la producción de ventajas comparativas producidas por el Estado (fijación de la constructibilidad del suelo o floor area ratio, ${ }^{4}$ provisión de infraestructura en el sector, subsidios a la demanda, exenciones impositivas, o incluso presiones por cambios reglamentarios). Esta renta es de carácter oligopólico (o monopólica de clase, según Harvey, 1974) en la medida en que las posibilidades tecnológicas y financieras, actualmente concentradas en un grupo relativamente reducido de agentes productores inmobiliarios, se constituyen como la única posibilidad de materializar dicha renta.

Ambas rentas, capitalizada y potencial, están relacionadas dialécticamente y casi siempre implican algún grado de contradicción. La captura monopólica de la renta potencial en un determinado barrio implica despojamiento, si no de suelo, sí del potencial residencial o económico que éste ofrece; ya que este tipo de renta de suelo no depende sólo del incremento de su límite máximo posibilitado por la constructibilidad del suelo, sino también de la capacidad de reducir el valor de la renta capitalizada socialmente por los pequeños propietarios a través de diversas formas, ya sea por medio de un pago monopsónico al momento de la transacción, o la reducción intencionada del valor a través de acciones concretas tendientes a la devaluación de las propiedades del sector.

Una baja renta de suelo capitalizada por un núcleo familiar residente no da cuenta del valor de uso de la propiedad que se negocia e implica una desposesión concreta del potencial de pago por residencia de reemplazo en otro lugar. De tal forma, cuando se trata de una devaluación generalizada de la renta de suelo socialmente capitalizada, se dan las condiciones necesarias para la existencia de gentrificación en ese lugar. El presente artículo se propone estudiar el caso de Nuñoa a la luz de esta teoría.

El análisis se realizó siguiendo una metodología de tres pasos. Primero, delimitación de la zona de estudio (contiene 45 proyectos de renovación urbana construidos entre 2000 y 2010), junto con un estudio cronológico de las principales modificaciones normativas realizadas por la autoridad municipal que afectan el suelo en el sector aquí estudiado, este estudio está basado en documentación oficial de zonificación y normativa de suelo y se apoya con entrevistas a funcionarios municipales y activistas vecinales.

\footnotetext{
${ }^{4}$ Es decir el factor de máxima construcción permitida a partir del tamaño del predio.
} 
Segundo, una estimación de rentas de suelo capturadas por inmobiliarias a través de cada proyecto, extraídas de la suma de los precios del total de unidades puestas a la venta en cada edificio, descontando luego costos de producción; es decir, costos de suelo pagado más construcción más ventas; todos valores procesados en $\mathrm{UF}^{5}$ y UF $/ \mathrm{m}^{2}$ y entregada su correspondencia a valores en dólares de Eevu ${ }^{6}$. Los datos son extraídos de precios publicados en portales de internet de mercado inmobiliario $y$ ofertas en la prensa, además de la exhaustiva revisión de planos de arquitectura en los expedientes de edificación, entregados por cada inmobiliaria a la municipalidad.

Tercero, un procesamiento de la renta de suelo capitalizada por los propietarios antiguos de los 179 predios que fueron adquiridos por inmobiliarias entre 2000 y 2010, y posteriormente fusionados en paños de suelo mayores, para ser luego explotados a través de edificación en altura.

\section{1. Ńuńoa 2000-2010, un contexto de cambios urbanos radicales}

A principios de la década de los noventa, el Ministerio de Vivienda y Urbanismo (Minvu) nacional amplió, a una escala intercomunal, la relativamente exitosa zona de renovación definida en 1987 para la comuna de Santiago centro. Esta ampliación trajo consigo la instauración del Subsidio de Renovación Urbana (SRU) a fin de repoblar las comunas del pericentro y ampliar la actividad inmobiliaria hacia esas zonas. Desde entonces, un bono de 200 uf (alrededor de us \$ 4,000 según valor cambiario de 1990) equivalente a $10 \%$ del valor máximo de cada nueva unidad residencial a subsidiar, obtenible tras un periodo de ahorro mínimo un ańo, se ofrecería a los compradores de las nuevos apartamentos construidos en el interior de una Zona de Renovación Urbana.

El sistema de selección precisamente priorizaba a los postulantes de mayor capacidad de ahorro, mientras que la Zona de Renovación Urbana, tras algunos años, se expandiría a su tamaño actual de alrededor de 8,500 hectáreas (aproximadamente 1/8 de la extensión actual de la metrópolis), comprendiendo 10 municipios (uno central y nueve pericentrales) del total de las 34 comunas metropolitanas.

De esta forma, a mediados de la década de 2000, las comunas pericentrales ya habían surgido como importantes soportes para la inversión

${ }^{5}$ La Uf (unidad de fomento) es una unidad de cuenta utilizada en Chile, autoajustable de acuerdo a la inflación económica nacional. A octubre 2013, una uf equivale a $\$ 23,000$ pesos chilenos, es decir unos us $\$ 46$ aproximadamente.

${ }^{6}$ Sólo se cuantifica aproximadamente la renta potencial capturada por inmobiliarias, ya que en rigor es imposible desagregar el valor de la materia construida de la unidad de apartamento respecto a la renta puramente originada por suelo. Se trata de una limitación metodológica que en ningún caso invalida el potencial explicativo y tendencial del método aquí ocupado. 
del mercado inmobiliario, con administraciones locales, en su mayoría, expectantes de generar modificaciones permisivas en sus ordenanzas de suelo y construcción. La comuna de Nuñoa fue pionera en este sentido.

En 1989, el municipio de Nuuñoa reemplazó su primer Plan Regulador Comunal (PRC) que databa de 1967. Anteriormente, durante la operación del PRC de 1967, la comuna había incorporado a su territorio construcciones de media altura. En cambio, la zonificación modificada del PRC de 1989 estableció dos tipos de zonas: una de renovación y densificación en altura, bordeando los principales ejes, y otra más protegida en el interior de los barrios. Fue entonces cuando se creó la primera iniciativa de valorización patrimonial con la Zona de Conservación Histórica ( $\mathrm{zCH}$ ), correspondiente al conjunto de la caja de ahorro de Empleados Particulares Elías de la Cruz (Fotografía iI). Esta disposición promovía el desarrollo de macro áreas de bordes con una dinámica más intensa en torno a las vías estructurantes.

$\mathrm{Al}$ poco tiempo, la comuna comenzó a recibir un mayor porcentaje de apartamentos que casas unifamiliares, lo que modificó ostensiblemente la vocación urbana residencial de Ñuñoa (Aguirre y León, 2007). Fue entonces que la misma autoridad comunal que había promovido la elaboración del PRC de 1989, ${ }^{7}$ determinó que los resultados de la dinámica de transformación urbana eran aún reducidos si se comparaban con el desarrollo de comunas vecinas como Santiago y Providencia. Como se muestra en el cuadro 1, en lo normativo, y a diferencia de las zonas de renovación de mayor atracción de la inversión inmobiliaria en altura, las zonas de densificación del PRC de 1989 establecían coeficientes de constructibilidad máximos de 2.5 y 3.0; este factor fue entonces visto como responsable de la ausencia de renovación y densificación a lo largo de los ejes primordiales, incluso avenida Irarrázaval, principal arteria de la comuna donde no se establecía límite de altura (Municipalidad de Nuuñoa, 2002) y, por ende, responsable del despoblamiento comunal registrado por los censos nacionales de población (INE, 1992, 2002).

A partir de este punto, la acción municipal se plasmó en dos políticas específicas. Primero, logró implementar en la comuna tres zonas de aplicación del Subsidio de Renovación Urbana (SRU), buscando generar confianza del mercado inmobiliario y asegurando la demanda por vivienda. Segundo, realizó una nueva modificación al PRC, realizada en 2004, que introdujo nuevas subzonas: Z1a, Z2a y Z3a (cuadro 1 y mapa II), para flexibilizar aún más las normas de edificación en determinadas zonas a fin de generar una atracción que pudiese competir con las comunas

\footnotetext{
${ }^{7}$ Pedro Sabat se ha desempeñado en el cargo de alcalde de la comuna de Nuuñoa en dos periodos: primero, como alcalde designado en la dictadura militar durante 1987 y 1989 y, segundo, desde 1996 en adelante, logrando cinco elecciones democráticas consecutivas.
} 


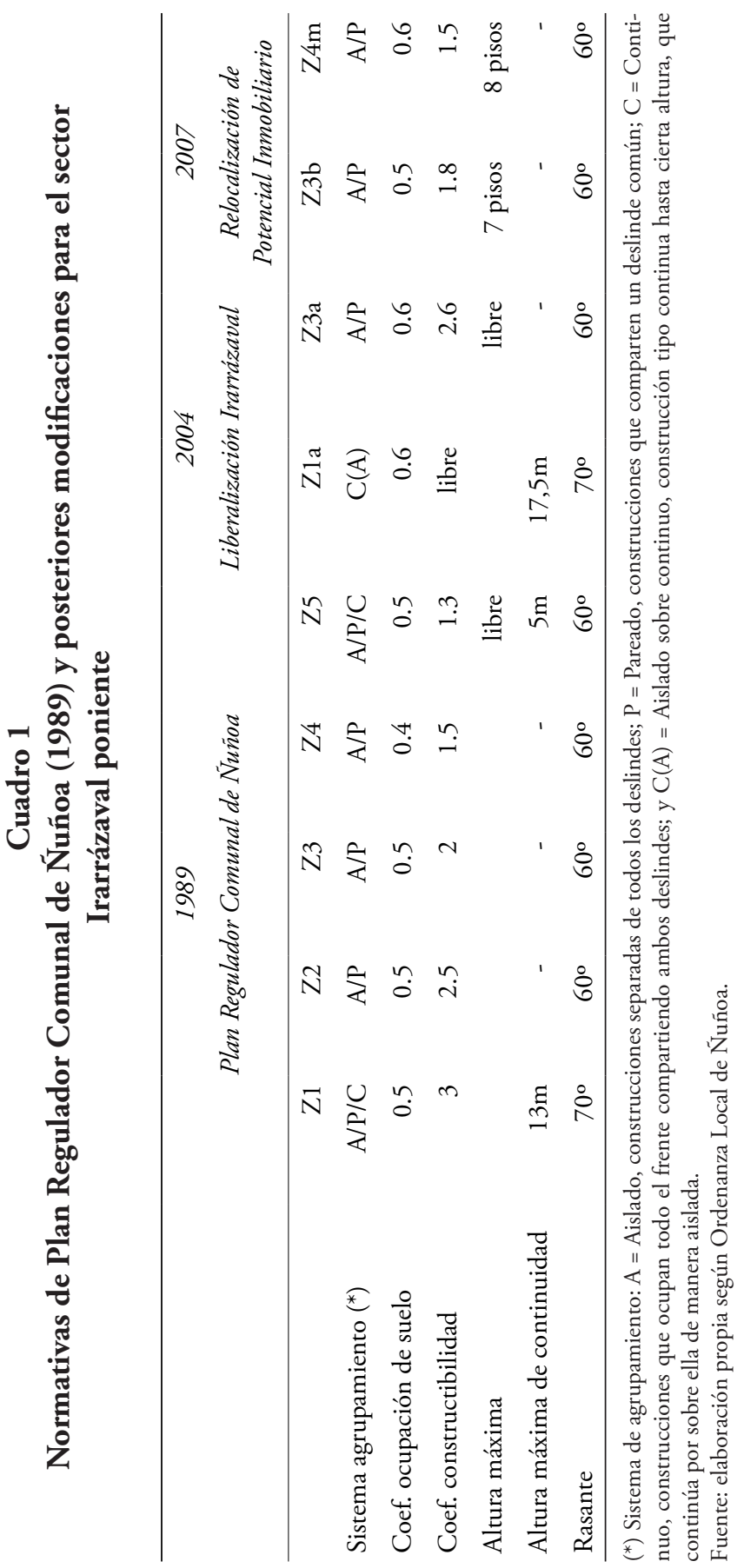



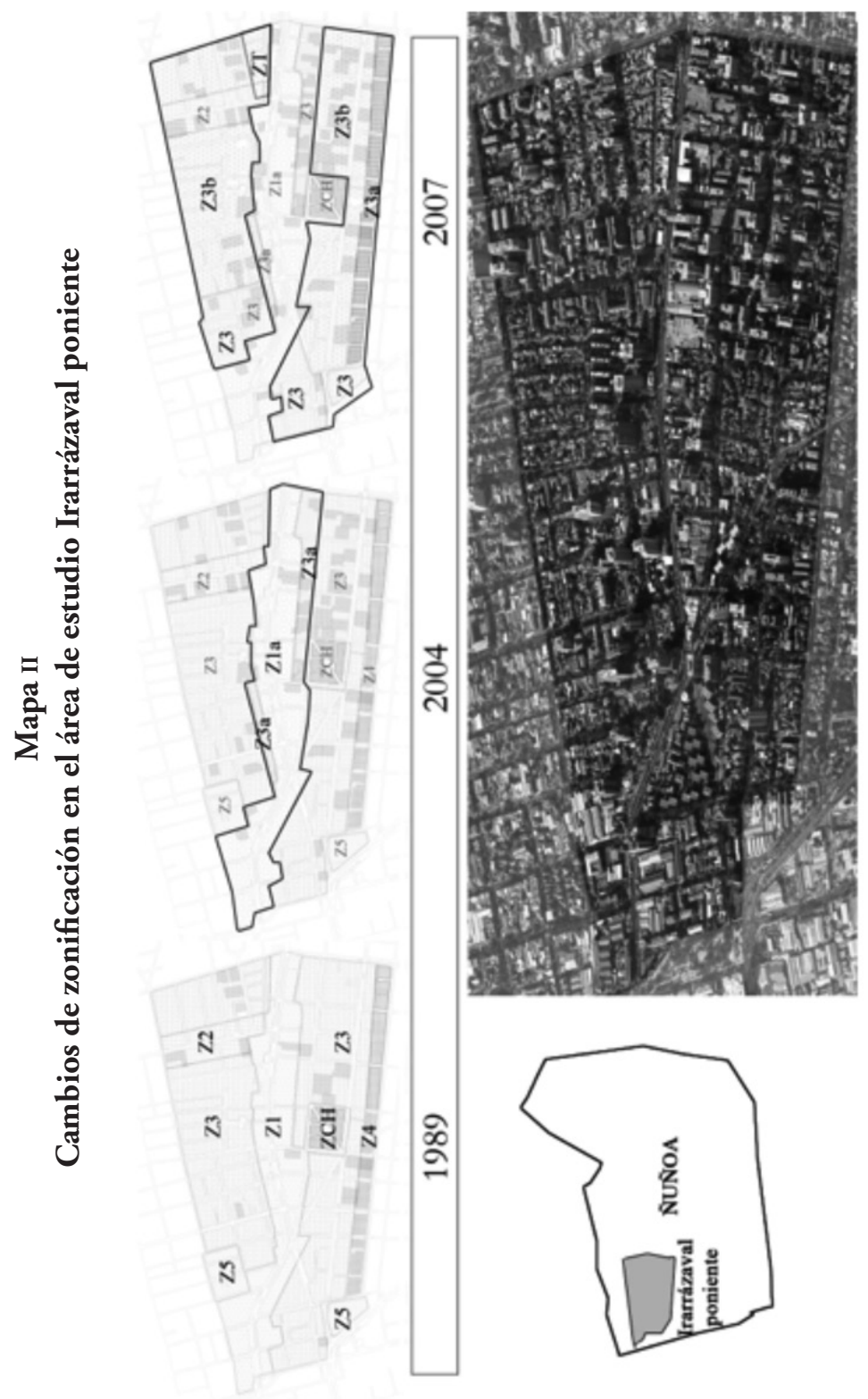
vecinas y producir un aumento generalizado del valor de suelo en la mayor parte de Núñoa.

Paralelamente, la inversión pública gubernamental se había hecho presente en 1997, al mejorar la conectividad comunal con la llegada del Metro a lo largo del límite poniente del municipio y la repavimentación de las avenidas conectoras intercomunales Sucre y Dublé Almeyda, que corren aledańas y paralelas a Irarrázaval. El efecto de estas iniciativas combinadas fue casi inmediato, como se aprecia en la gráfica I, se generó un alza exponencial en el número de permisos de edificación otorgados por la Dirección de Obras Municipales (DOM) a partir de 2005, se alcanzaron cerca de 600 mil y 700 mil metros cuadrados aprobados en 2006 y 2007, a través de 44 y 42 proyectos inmobiliarios respectivamente, y más de 550 mil metros cuadrados solamente residenciales en 2006.

Esto constituye, para el 2006, un más que notable 12\% de la edificación residencial en el total de las 34 comunas que componen el Gran Santiago (sII, 2011). Producto de lo anterior, la edificación residencial en altura se intensificó al interior de la zona Irarrázaval poniente, alcanzando en 2005 cerca de un tercio de la edificación total en la comuna, y alrededor de 41\% de la edificación total en 2006.

\section{Gráfica I}

\section{Evolución 1997-2010 del volumen aprobado para construcción en $\mathbf{m}^{2} \mathbf{y}$ volumen total de derechos municipales pagados por permiso de construcción}

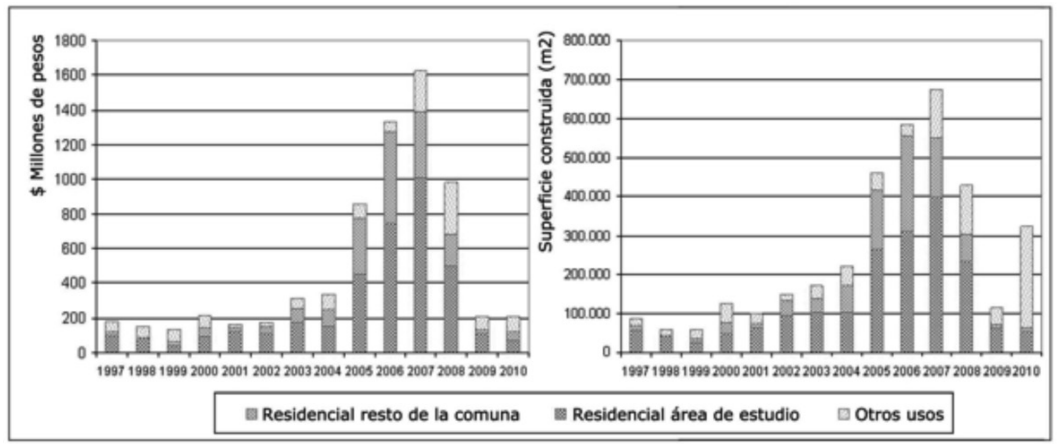

Fuente: elaboración propia con base en datos de distintos años de la Dirección de Obras Municipales (Dom) Nuñ́oa.

Sin embargo, al 2009, la zona Irarrázaval poniente ya se había enfriado y al año siguiente la comuna presentaba una caída notable de edificación residencial con una recuperación de la construcción para usos no residenciales, ello producido parcialmente por la crisis económica global 
que restringió, durante 2008 y 2009, el acceso al crédito bancario, tanto para las inmobiliarias productoras de vivienda como para la demanda por residencia. Lo anterior se sumó a los efectos psicológicos contrarios a la edificación en altura generados por el terremoto del 28 de febrero de 2010 (que redujo momentáneamente la demanda por apartamentos en la zona central del país). Sin embargo un tercer factor, probablemente de mayor injerencia, fue la aplicación en esta zona de un cuadro normativo más restrictivo, incorporado en la modificación de $2007,{ }^{8}$ tal modificación respondió en gran medida a la presión ciudadana por mayor regulación del suelo.

La preferencia de los productores inmobiliarios, entre 2004 y 2008, por desarrollar proyectos tanto a lo largo de los ejes principales como, mayormente, al interior de los barrios de menor densidad y altura, generó diversos conflictos con residentes, en su mayoría propietarios, que fueron testigos del reemplazo de numerosas edificaciones de interés arquitectónico de los efectos del proceso de construcción y de una fuerte alteración de las condiciones ambientales y visuales producida por la inusitada concentración de emprendimientos inmobiliarios en altura.

Opuestos a lo que denominaron masacre urbana, ${ }^{9}$ surgieron diversos grupos de vecinos, generalmente organizados alrededor de entidades barriales, que fueron fortaleciendo sus lazos inter-barriales. Esta convergencia dio lugar, en 2006, a la Red Ciudadana por Nuñoa (Mlynarz, 2007), la cual tuvo su clímax de adhesión y manifestación a mediados del mismo año, con una intensa movilización vecinal por una modificación al PRC que preservara las condiciones ambientales que caracterizaron la comuna durante el siglo xx, modificación que fue realizada en el sector Irarrázaval poniente en 2007.

No obstante, dicha reforma prácticamente no contempló instancias de participación ciudadana relevante en su elaboración, se limitó al mínimo de audiencias públicas contenidas en la Ley General de Urbanismo y Construcciones, lo que en vez de reducir el malestar social vecinal, lo acrecentó.

En términos generales, la nueva modificación al PRC en 2007 estableció una altura baja y media en los barrios del interior de la comuna, compensando tal disminución con el aumento de la alta constructibilidad hacia otras zonas de máxima densificación en los bordes del territorio de Nuñoa, a saber: a) al sur de la comuna, en suelo de antiguo uso industrial

\footnotetext{
${ }^{8} \mathrm{Si}$ bien aquellos proyectos ya habían conseguido permiso previo de edificación (con las condiciones normativas de 2004), al interior del sector Irarrázaval poniente se tendría un margen de tres años para desarrollarlos, según establece la ley chilena en el Artículo 1.4.17. de la Ordenanza General de Urbanismo y Construcciones (Minvu, 2007b).

${ }^{9}$ Veáse http://rciudadanapornunoa.blogspot.com/2010/10/la-masacre-urbana-de-nunoa.html
} 
y residencial de sectores de nivel socioeconómico medio-bajo y bajo, y b) al oriente, en el borde de la recientemente inaugurada línea cuatro del Metro.

En otras palabras, sin eliminar la alta edificabilidad potencial incorporada en 2004 a su plan regulador, el municipio realizó un traslado de esta constructibilidad y promovió nuevas zonas de atracción con una alta renta potencial de suelo que previamente no había interesado al capital inmobiliario.

Lo que hizo el municipio de Ńuñoa entre 1989 y 2007 no es excepcional. La tendencia de edificación residencial en altura se ha extendido por la totalidad del centro y pericentro del área metropolitana de Santiago, en gran medida gracias a una política general que aporta varios mecanismos flexibilizadores de las condiciones fijadas por los planes reguladores comunales.

Ejemplo de ello son los artículos 63 y 109 de la Ley General de Urbanismo y Construcciones (LGUC), que ofrecen un incremento de $30 \%$ en la constructibilidad por fusión de terrenos y de diversos incentivos por conjunto armónico; así como los artículos 6.1.5., 2.1.11. y 5.1.4. de la Ordenanza General de Urbanismo y Construcción (ogUc), que respectivamente permiten descontar la superficie construida en áreas comunes del cálculo de constructibilidad (cuando éstas no superan 20\% del total edificado) y presentar un estudio de proyección de sombras para sobrepasar la limitación de rasante, así como disminuir los derechos municipales por permiso de edificación al repetir unidades y plantas (Minvu, 2007a, 2007b).

Así también, económicamente, operan los incentivos tributarios tanto a la oferta como a la demanda contenidos en el Decreto Ley DL 910 de 1975 (que gratifica a las constructoras con 65\% de devolución del IVA por material de construcción), y en el Decreto con Fuerza de Ley DFL 2 de 1959 (que exime del pago de contribuciones territoriales a los propietarios de bienes inmuebles urbanos durante 20, 15 y 10 ańos para viviendas cuya superficie es inferior a $70 \mathrm{~m}^{2}$, cuya superficie es de entre $70 \mathrm{~m}^{2}$ y $100 \mathrm{~m}^{2}$, y de entre $100 \mathrm{~m}^{2}$ y $140 \mathrm{~m}^{2}$, todas ellas denominadas viviendas económicas), lo que produce un contexto atractivo de mercado, generalmente deseado por las autoridades tanto a nivel comunal como nacional.

A esto se suma, como ya se mencionó anteriormente, la inexistencia en Chile de mecanismos de recuperación estatal de plusvalías generadas, así como la elusión del Impuesto Global Complementario (IGC) por parte de los propietarios o accionistas de las empresas inmobiliarias, ${ }^{10} \mathrm{y}$

\footnotetext{
${ }^{10} \mathrm{El}$ IGC grava hasta $40 \%$ de las rentas de las personas, pero desde 1984 la ley chilena es permisiva respecto a su elusión cuando se trata de dueńos de empresas. Ello se produce mediante el no retiro de utilidades desde las empresas; este capital acumulado permite a) usufructo particular de
} 
la exención al impuesto a la renta que beneficia a los Fondos de Inversión Privados (FIP) asociados a la producción de proyectos inmobiliarios, ${ }^{11}$ modalidad que entre 2004 y 2010 tuvo una incidencia de $12.8 \%$ en este rubro (Cattaneo, 2011).

Un incentivo adicional indirecto son las iniciativas de valorización patrimonial. En el caso de Nuuñoa, el Consejo de Monumentos Nacionales ha aprobado tres Zonas Típicas (zT) - una de ellas dentro del área de estudio- con lo que, además de la afección misma que significa la declaratoria, se generan efectos de intensa valorización de los terrenos circundantes a estas zonas, al ser una localización favorable para el desarrollo de proyectos inmobiliarios aledaños (por vistas aseguradas de paisajes urbanos tradicionales, mayor soleamiento, sensación de identidad barrial, etc.) y se detonan y refuerzan procesos de renovación en sus bordes.

Como se ve, en este caso existe una serie de mecanismos legales, políticos y económicos que, combinados, aseguran la explotación de la renta de suelo a través del mejor y más intenso uso del espacio urbano en determinadas zonas, en este caso, Nuuñoa poniente entre 2004 y 2007.

\section{Impacto económico-social en comuna de Nuuñoa y sector Irarrázaval poniente}

La comuna de Nuñoa, desde la intensificación de la producción inmobiliaria alojada en ella en 2004, ha incrementado en términos generales el precio de su suelo. Si a finales de la década de los ochenta Núñoa expresaba precios de suelo por debajo de las $4.5 \mathrm{uF} / \mathrm{m}^{2}$ (Us\$200/ $\mathrm{m}^{2}$ ), en 2010 esos valores se habían aumentado a $22 \mathrm{uF} / \mathrm{m}^{2}$ (Us\$ $1000 / \mathrm{m}^{2}$ ); es decir, cerca de $400 \%$ de incremento en valor real en 20 años.

Comparativamente, la tasa de incremento de los valores de suelo ofertado en Nuñoa es bastante mayor a las comunas vecinas de Providencia $(108 \%)$ y Santiago (107\%), que siguen en gran medida los patrones generalizados actuales de encarecimiento del suelo urbano de la región y la metrópolis para el mismo lapso.

Nuñoa intensifica esos valores producto de la alta demanda por locación inmobiliaria y la serie de factores facilitadores, entre ellos la modificación de 2004 del PCR, que acelera el proceso de encarecimiento de suelo por sobre la tendencia de las otras comunas. Incluso la modificación de 2007, indicada en el cuadro 1 y el mapa II, no causa el efecto

bienes de la empresa por parte de los dueños, b) incremento del valor de la empresa hasta conseguir un valor mayor en una eventual venta (operación que tampoco será gravada impositivamente) y c) adquisición de acciones de la misma empresa para así incrementar su valor en la bolsa. Se estima que, acumulativamente, en Chile el capital no retirado para eludir el global complementario asciende a us\$200 mil millones, es decir, el equivalente al piB chileno (Ramos, 2011).

${ }^{11}$ Veáse http://www.cchc.cl/wp-content/uploads/2012/01/Fondos-de-inversion-privados.pdf 


\section{Fotografía II}

Zonas de renovación en altura vistas desde el interior de barrios tradicionales de Nuuñoa: Elías de la Cruz

\section{y población de suboficiales}
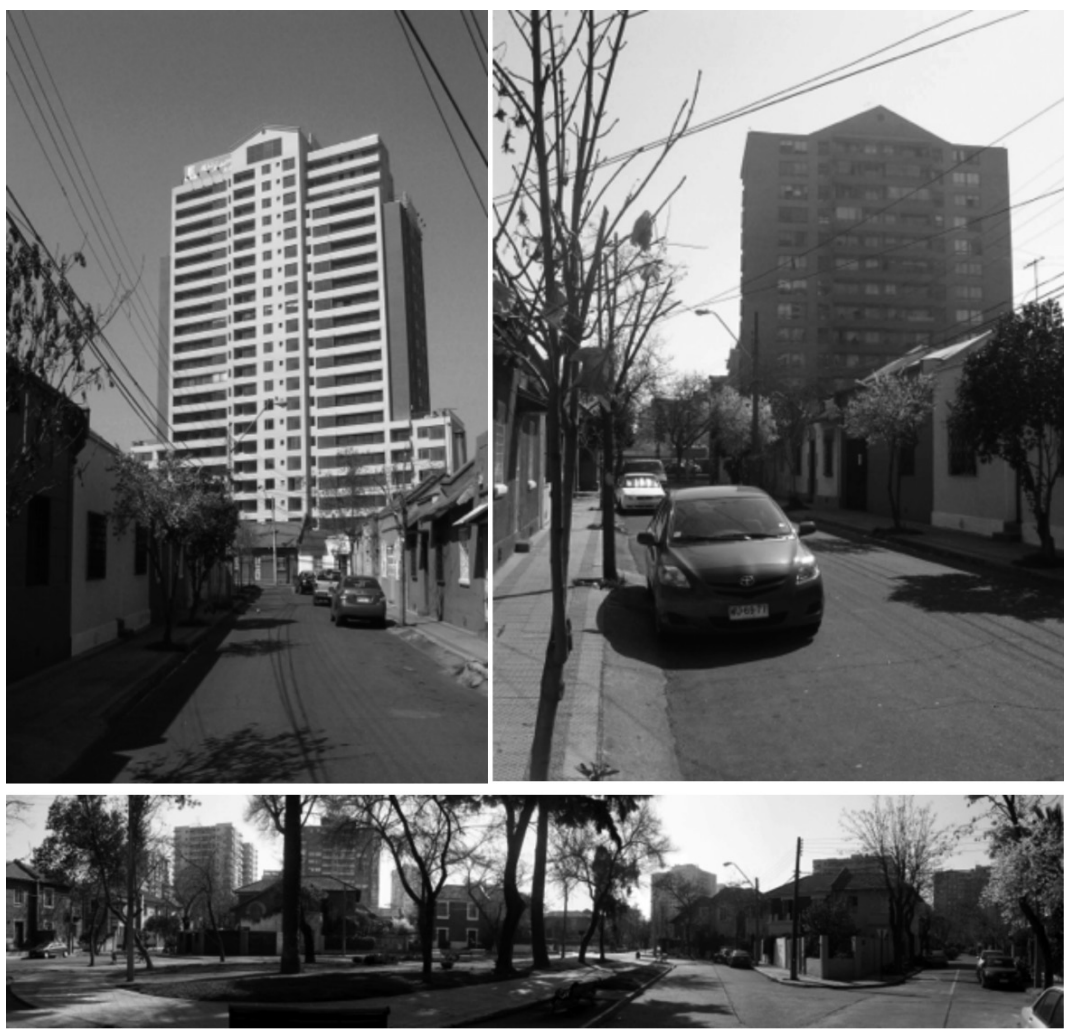

Arriba izquierda, zona típica suboficiales, visat interior hacia avenida Irarrazaval; arriba derecha, zona típica suboficiales vista contraria; abajo, zona de conservación histórica Elías de la Cruz, panorámica interior.

Fotos: Daniel Meza, 2010.

decreciente que supone el limitar alturas en ciertas zonas, lo que continúa la tendencia alcista del valor de suelo comunal.

El explosivo volumen construido en Núñoa entre 2005 y 2008 se traduce en la quintuplicación del impuesto internalizado por el municipio debido a permisos de edificación de obra nueva (que es $1.5 \%$ del presupuesto total de la obra), según expresa la gráfica I, con una ganancia obtenida por pago de esos derechos de construcción cercana a los us $\$ 700,000$ solamente dentro de la zona Irarrázaval poniente en 2006, equivalente a $23 \%$ del ingreso municipal generado por impuesto a la construcción. En contraste, el sector Irarrázaval poniente representa aproximadamente 1/15 o $6.5 \%$ de la superficie comunal. 
Para el 2007, el ingreso global percibido por derecho municipal de construcción de obra nueva en esta zona superaba los us\$ 36 millones, lo que representaba alrededor de $7.84 \%$ del presupuesto global municipal anual. ${ }^{12}$ Evidentemente, tan importante o más que el intento de revertir tendencias al deterioro del medio construido o al despoblamiento demográfico, la renovación urbana se configuraba como un elemento importante de captura financiera para el municipio de Núñoa.

Con el alza observada de los valores generales de suelo en la comuna se produjo una captura creciente de renta de suelo por parte de residentes propietarios, aunque en una mayor magnitud lo hicieron las empresas inmobiliarias. El cuadro 2 sintetiza resultados del análisis de producción inmobiliaria correspondiente al área de estudio a través de la observación y cálculo de renta de suelo en 45 casos de proyectos inmobiliarios (de un total de 68 existentes a la fecha), todos ellos cuya construcción se eleva sobre los siete pisos de altura. Se calculan promedios, valores mínimos y máximos, y desviación estándar para los factores expresados. Como puede apreciarse, la superficie predial utilizada por los edificios fluctúa entre 1,300 y 6,400 metros cuadrados.

Este valor permite entender que el consumo de suelo necesario para un proyecto de renovación en altura es en promedio de 4.05 predios (considerando que la superficie predial promedio de los predios preexistentes es de $689 \mathrm{~m}^{2}$ ), los cuales se proceden a limpiar (demoler la edificación existente) y fusionar para posibilitar la construcción nueva.

Tal fusión predial no es gravada impositivamente de acuerdo a la ley chilena. Los volúmenes conseguidos superan los 11 pisos, llegan incluso a 25 (posibles en zonas de altura libre acogiéndose a estudio de proyección de sombras). La densidad neta residencial conseguida en promedio supera los 1,900 habitantes por hectárea, un gran aumento, teniendo como referencia la densidad bruta de 100 hab/ha aproximados que arrojó el Censo de Población 2002 para la comuna (INE, 2002). Estos datos permiten calibrar grosso modo el impacto de la masa edificada en la renovación urbana del sector.

A través del dato obtenido en el Conservador de Bienes Raíces de Santiago (CBRs) observamos una renta capitalizada (pago por suelo) considerablemente más baja que la señalada, en términos globales, por los indicadores del Boletín de Mercado de Suelo de Santiago de la empresa consultora Trivelli (varios años); uno de los más utilizados en estudios de mercado de suelo en Chile, con un promedio de $16 \mathrm{uF} / \mathrm{m}^{2}$, llegando a un máximo de 25 unidades de fomento sobre metro cuadrado.

\footnotetext{
${ }^{12}$ Sumado a otros permisos de la producción inmobiliaria, tal como las ampliaciones, la cifra alcanza 8.18 por ciento.
} 


\section{Cuadro 2}

Edificios aprobados por Dirección de Obras Municipales (Dом) entre 1999 y 2010 (45 unidades)

\begin{tabular}{|c|c|c|c|c|c|}
\hline & & Promedio & $\begin{array}{l}\text { Desviación } \\
\text { estándar }\end{array}$ & Mínimo & Máximo \\
\hline \multirow{7}{*}{ 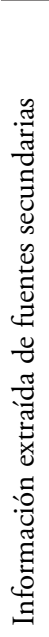 } & $\begin{array}{l}\text { Superficie predios originales } \\
\left(\mathrm{m}^{2}\right)\end{array}$ & 681 & 656 & 148 & 6,139 \\
\hline & $\begin{array}{l}\text { Superficie predial lograda por } \\
\text { Fusión }\left(\mathrm{m}^{2}\right)\end{array}$ & 2,639 & 1,136 & 1,303 & 6,400 \\
\hline & Altura de edificación (pisos) & 16 & 3.6 & 11 & 25 \\
\hline & $\begin{array}{l}\text { Coeficiente de Constructibili- } \\
\text { dad edificado }\end{array}$ & 4.62 & 1.48 & 1.95 & 7.83 \\
\hline & $\begin{array}{l}\text { Densidad neta proyectada (hab/ } \\
\text { ha) (considera hogares de cuatro } \\
\text { integrantes) }\end{array}$ & 1,961 & 750 & 996 & 3,825 \\
\hline & $\begin{array}{l}\text { Promedio } \mathrm{m}^{2} \text { por apartamentos } \\
\text { ofertados }\end{array}$ & 75.7 & 10.66 & 32.6 & 120 \\
\hline & $\begin{array}{l}\text { Promedio precio oferta aparta- } \\
\text { mentos (US\$) }\end{array}$ & 136,811 & 38,099 & 42,621 & 211,663 \\
\hline \multirow{6}{*}{ 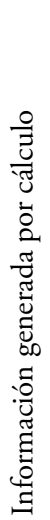 } & $\begin{array}{l}\text { Promedio precio unitario } \mathrm{m} \\
\left.\text { apartamento ofertado (US } \$ / \mathrm{m}^{2}\right)\end{array}$ & 1,741 & 183 & 1,280 & 2,516 \\
\hline & $\begin{array}{l}\text { Rentabilidad cuantificada } \\
\text { (ganancia neta/inversión) }\end{array}$ & $30.40 \%$ & 10.9 & $14.80 \%$ & $70.20 \%$ \\
\hline & Renta potencial bruta (Us\$) & $3,733,690$ & $2,234,297$ & 986,687 & $10,951,789$ \\
\hline & $\begin{array}{l}\text { Renta potencial por } \mathrm{m}^{2} \text { de } \\
\text { parcela de suelo desarrollada } \\
\left(\mathrm{Us} \$ / \mathrm{m}^{2}\right)\end{array}$ & 1,506 & 880 & 441 & 4,803 \\
\hline & $\begin{array}{l}\text { Renta capitalizada (social) } \\
\left(\mathrm{Us} \$ / \mathrm{m}^{2}\right)\end{array}$ & 773 & 249 & 411 & 1,190 \\
\hline & $\begin{array}{l}\text { Tasa de captura (potencial/ } \\
\text { capitalizada) }\end{array}$ & 3.03 & 1.39 & 1.74 & 10.19 \\
\hline
\end{tabular}

Fuente: elaboración propia con base en Informe de la DOM y el CBRs, así como de portalinmobilario.com.

En la sección siguiente se analizan estos valores en forma más desagregada y de manera evolutiva, pero por lo pronto basta decir que la renta potencial capturada por los desarrolladores, en promedio, triplica la renta capitalizada por los propietarios antiguos, generando lo que llamamos una tasa de captura de 3/1 y que alcanza máximos de 10/1. Se trata de una relación baja comparada con los diferenciales encontrados en la comuna de Santiago-centro, que en promedio ascienden a una relación 
de 14/1 entre la renta corporativamente capturada versus la renta socialmente capturada.

La diversidad de tasas de ganancia entre distintos proyectos de inversión revela un alto grado de riesgo inmobiliario y, en específico, parece ser reflejo de la incidencia de la diversidad de productos residenciales ofrecidos, precios de venta $y$, fundamentalmente, la capacidad dispar entre unas empresas y otras de conseguir un precio de transacción de suelo favorable. Por otra parte, la rentabilidad financiera, es decir, la relación entre montos de inversión (suelo, construcción y costos asociados) y la ganancia neta de cada proyecto (suponiendo todas las unidades residenciales vendidas al precio ofertado de mercado) muestra valores de un promedio de $30 \%$ de rentabilidad, superior a la media anunciada vox pópuli por las inmobiliarias chilenas de $20 \%$ de rentabilidad.

Como muestra el cuadro 2, la dispersión en la captura (social) de la renta capitalizada es alta. En la figura I cada punto representa una venta de suelo a una inmobiliaria, de tal forma que varios puntos ubicados en la misma columna representan transacciones de suelo realizadas con fin de generar pańos para un mismo proyecto, o varios proyectos construidos en ese periodo.

De esta forma, fue posible identificar la alta diversidad de precios pagados por suelo en una misma operación, con un máximo observado de casi $16 \mathrm{uF} / \mathrm{m}^{2}$, y un mínimo de $4.5 \mathrm{uF} / \mathrm{m}^{2}$ pagados a propietarios antiguos, así como una desviación estándar observada de cuatro. Esto implica que propietarios vendedores no necesariamente alcanzan la valoración de mercado que, según el boletín de mercado de suelo convencional (Trivelli), a partir de 2005, fluctúa entre 20 y $25 \mathrm{uF} / \mathrm{m}^{2}$, lo que indica un amplio diferencial de captura de renta de suelo también entre distintos propietarios de suelo.

Al mismo tiempo, la captura potencial de la renta fue motor para otros fenómenos asociados. La implementación de la modificación liberalizadora de 2004 significó un proceso intensivo de compra-venta de terrenos para dar lugar a la construcción de los proyectos actualmente construidos. Los terrenos transados previos al año 2004 tienden a ser mayores y, anteriormente, de uso comercial. Sin embargo, entre los años 2004 y 2007 , por la intensificación de la demanda de suelo, esta situación cambia, prevalece la compraventa de terrenos residenciales con tamaños inferiores a $400 \mathrm{~m}^{2}$ en al menos un tercio de los casos, obviamente se necesita una mayor cantidad de predios para lograr la fusión requerida para la edificación en altura.

Asimismo los predios resultantes fusionados tienden también a ser gradualmente más pequeños, se estabilizan en $2,500 \mathrm{~m}^{2}$ a partir de 2003 , aunque la superficie nueva construida en éstos no representa un alza 
contundente que se ha mantenido constante en volúmenes cercanos a $14,000 \mathrm{~m}^{2}$ por edificio. Aunque se utilizaban terrenos de superficie dos a tres veces menor que los que se ocupaban diez años atrás, actualmente se genera un uso al menos cuatro veces más intenso, posibilitado por los cambios en la normativa urbana local, específicamente por coeficientes de constructibilidad que se alzan considerablemente en 2004.

Un volumen de edificación mayor en predios reducidos implica necesariamente mayor altura y generalmente un efecto ambiental mayor, que se externaliza al resto de los predios circundantes por cono de sombra y pérdida de privacidad visual, sin hablar del eventual dańo físico a la estabilidad de los predios colindantes, generado por excavaciones durante la construcción.

El volumen de construcción ascendente ha permitido la producción de un mayor número de unidades habitacionales, con un tamaño promedio de apartamentos constante alrededor de $75 \mathrm{~m}^{2}$. A principios de la década de 2000, el número de unidades habitacionales por proyecto era levemente mayor a 80. Diez ańos más tarde, esta cifra superaba las 120 unidades por proyecto. La densidad neta estimada manifiesta una tendencia sostenida al alza que los últimos años bordea los 2,500 habitantes por hectárea. Si bien, la última modificación del PRC de 2007 establece densidad neta máxima de 1,800 hab/ha, esto sólo rige para las subzonas propuestas ese año, no se aplica al resto de la comuna compuesta por las zonas más liberalizadas.

Junto con esta tendencia a la mayor producción de unidades residenciales, los precios de venta de éstas también aumentaron drásticamente, compensando así las alzas del mercado de suelo. El valor promedio relativo de unidades residenciales se incrementó en $16 \%$, de $32 \mathrm{uF} / \mathrm{m}^{2}$ (Us\$ $1,536 / \mathrm{m}^{2}$ ) en 2000 a un peak promedio de $37 \mathrm{uF} / \mathrm{m} 2$ (us\$ 1,776) en sólo 6 años. Notablemente, se produce una leve declinación a partir de 2007, probablemente debida a una saturación y sobre stock ofertado con una desaceleración de la oferta inmobiliaria en este nicho de mercado, el precio observado de oferta de residencia se estabiliza -para la zona de Irarrázaval poniente- en $36 \mathrm{uf} / \mathrm{m}^{2}$ a partir de 2008, en adelante.

De esta manera, la posibilidad de edificar un mayor volumen útil transable en terrenos sin importar cuan pequeños resultaban, con unidades residenciales reducidas y un alza en el valor del metro cuadrado ofertado, generaron desde mediados de la década de 2000, cuantiosas rentas potenciales capturadas por productores inmobiliarios.

La figura in permite observar que la captura social de la renta capitalizada experimenta un aumento bastante más conservador que la renta potencial, si bien ambas van al alza. Singularmente, en 2000, el primer tipo de renta apenas alcanzaba un valor por debajo de la segunda, deno- 
tando la casi inexistencia de rent gap en la zona, es decir, no existía un mercado inmobiliario de renovación urbana verdaderamente rentable, pero ya en 2005 la renta potencial casi duplica la renta capitalizada, relación que continúa en aumento hacia el 2009, con una disminución posterior en 2010, producto de las modificaciones al PRC del año 2007, los efectos de la crisis inmobiliaria global, y los efectos psicológicos del terremoto en 2010.

En términos brutos, la renta potencial capturada íntegramente por inmobiliarias aparece como un valor inicial (año 2000) por debajo de las $20 \mathrm{uF} / \mathrm{m}^{2}$, pero que en 2008 aumentó a $40 \mathrm{uF} / \mathrm{m}^{2}$ de terreno desarrollado. Analizados de manera puntual aparecen cuatro proyectos que generan renta potencial por encima de las $50 \mathrm{UF} / \mathrm{m}^{2}$ (los cuales se localizan en el borde mismo de Irarrázaval, superando todos ellos los 18 pisos de altura) y dos con rentas generadas cercanas a las $100 \mathrm{uF} / \mathrm{m}^{2}$.

En contraste, ninguno de los casos analizados de renta capitalizada socialmente supera las $30 \mathrm{UF} / \mathrm{m}^{2}$, y sólo en 2006, la renta capitalizada socialmente superaría la brecha de $20 \mathrm{uf} / \mathrm{m}^{2}$ en dos casos. De 2004 a 2007, es decir, el tiempo de liberalización máxima de la normativa local de construcción para la zona Irarrázaval poniente, en $55 \%$ de los casos de suelo pagado a sus propietarios, el valor no supera las $15 \mathrm{UF} / \mathrm{m}^{2}$, mientras que el Boletín de Mercado de Suelo convencional (Trivelli) indica peaks de $25 \mathrm{uF} / \mathrm{m}^{2}$.

Según los datos de la figura I, en al menos $40 \%$ de los casos se estaban pagando valores inferiores a los de mercado; para el mismo lapso, sabemos que $16 \%$ de los casos eran de predios bajo los $300 \mathrm{~m}^{2}, 34 \%$ bajo los 400 $\mathrm{m}^{2}$ y $57 \%$ bajo los $500 \mathrm{~m}^{2}$; es decir, con alta probabilidad eran predios de uso residencial. Suponemos que un pago por debajo del valor referencial de mercado implica una pérdida de valor de uso por parte del propietario.

En términos de una eventual compensación, para un predio de 300 UF se requiere un pago de suelo de al menos $11 \mathrm{uF} / \mathrm{m}^{2}$ para lograr equiparar el precio promedio de 3,200 Uf (Us\$ 136,811) que cuesta un apartamento nuevo en la zona de tamaño notablemente inferior $\left(75 \mathrm{~m}^{2}\right)$ al suelo vendido. Con los valores predominantes de renta capitalizada, los dueños de predio de dimensiones menores probablemente estaban y están en una condición bastante complicada para conseguir relocalización en el mismo barrio.

El intenso actuar del mercado inmobiliario entre 2003 y 2008 elevó de manera abrupta los precios promedio de suelo, generando amplias posibilidades potenciales de ganancia por venta de suelo para sus propietarios. Sin embargo, como se aprecia en los datos aquí presentados, ello beneficia sólo a quienes lo hicieron en el debido momento, ya que no 
ocurre lo mismo para la mayoría de propietarios que no lograron vender a precio de mercado, o que tomaron decisiones muy por detrás de las ofertas generadas por las inmobiliarias, y por ende debieron mantener sus propiedades estancadas o en simple desvalorización, unido al costo ambiental originado por las externalidades de la construcción en altura.

Como se aprecia, en este tipo de mercados existe un muy alto grado de incertidumbre y virtual competencia, incluso a nivel de vecinos potencialmente oferentes.

\section{Figura I}

Evolución del promedio trimestral de valor de suelo del Boletín de Mercado de Suelo convencional para zona Irarrázaval poniente (línea) y registros de renta capitalizada por compra-venta de terrenos para proyectos en altura (puntos)

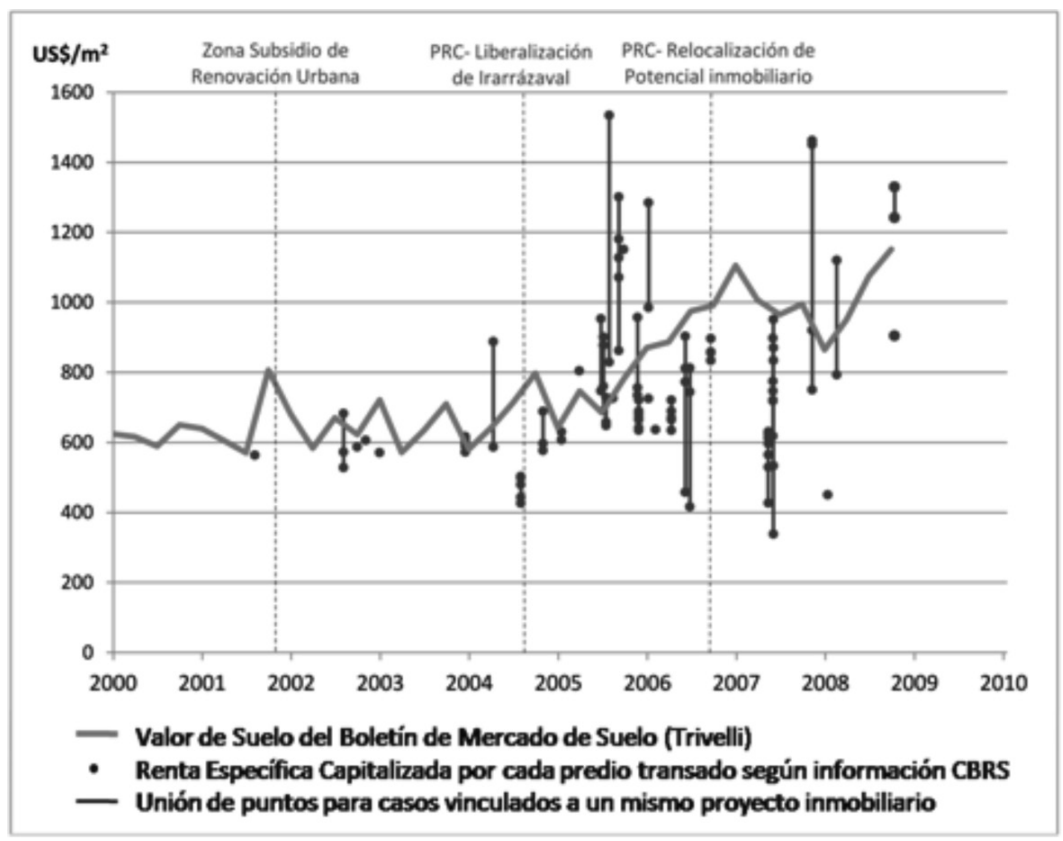

Fuente: elaboración propia en base en CBRs y Boletín de Mercado de Suelo de Santiago (Trivelli, 1987 2009). 


\section{Figura II}

\section{Rentas capitalizadas y potenciales de suelo}

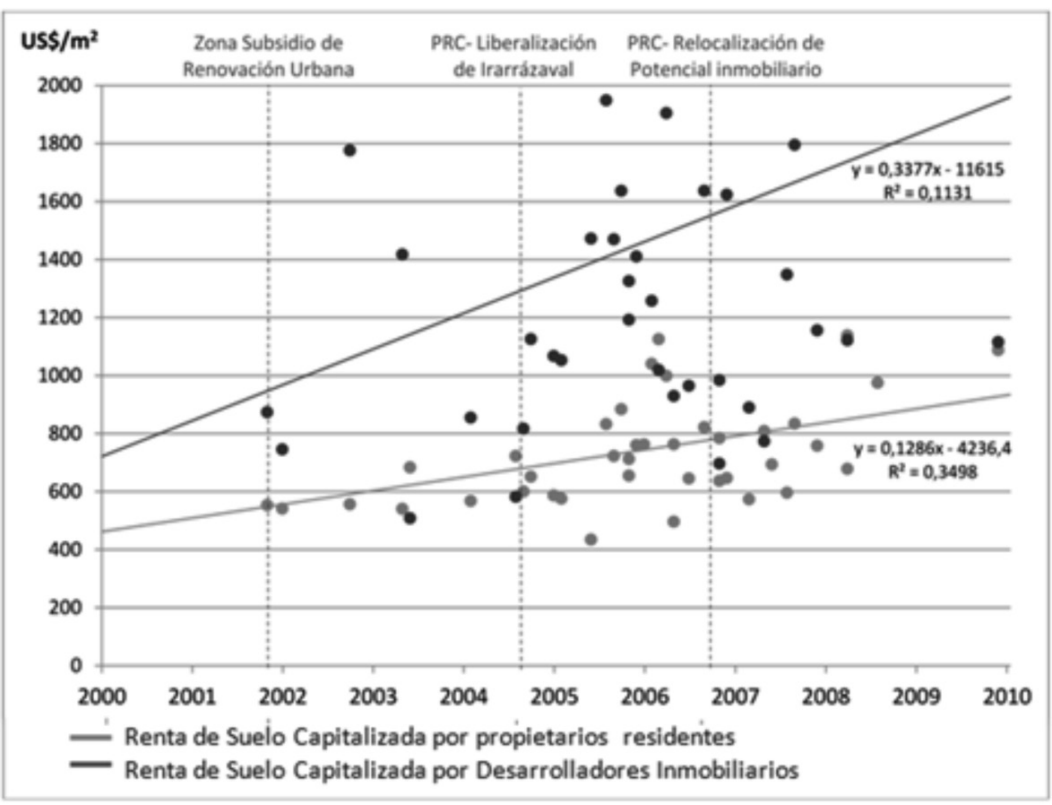

Fuente: elaboración propia con base en información de DOм Nuñoa, СвRS y sitio portalinmobiliario.com.

\section{Conclusiones}

El caso de Irarrázaval poniente corrobora varias de las condiciones características de los modelos de neoliberalismo urbano globales. En primer lugar, aparece una intensificación espacial y escalar de la inversión inmobiliaria en función de los cambios normativos generados por gobernanza local municipal, confluyente con los objetivos rentabilizadores y de localización del sector inmobiliario privado. El anclaje del capital al lugar se produce a través de condiciones normativas de suelo atractivas y garantías impositivas de carácter nacional. Asimismo, la fluidez y volatilidad de la inversión privada dependen en gran medida de una serie de modificaciones normativas consecutivas, que flexibilizan y luego restringen la rentabilidad del suelo urbano.

Por otra parte, las administraciones políticas locales asumen el riesgo de enfrentar la emergencia de activismo vecinal como contra-respuesta a sus objetivos pro-empresariales. En tal sentido, el municipio de Nunñoa aparece menos como un regulador del suelo y más como un actor de mercado que ofrece constructibilidad de suelo al mercado. Ello no significa que, con posterioridad, el municipio no actúe como redistribuidor 
de los beneficios económicos obtenidos por impuesto a la construcción a través de la provisión de bienes públicos y servicios, aunque sí debe ser aceptado que el municipio monopoliza las modificaciones normativas a través de decisiones de naturaleza inconsulta a la sociedad.

Efectivamente, se manifiesta un proceso de producción inmobiliaria que se impone sobre el territorio de Nunnoa y sus propietarios-residentes, quienes están en una relación dispar frente al agente productor inmobiliario, como lo demuestran en parte los incrementos de distinta magnitud de las trayectorias de las rentas de suelo capturadas por propietarios y desarrolladores respectivamente.

Sin embargo, ello no implica siempre desposesión del valor de uso de la renta capitalizada o la existencia de una suerte de presión por desplazamiento en condiciones económicas desventajosas (ergo, gentrificación), aunque sí se induce que para un porcentaje no menor de pequeños propietarios, usualmente de los predios de dimensiones menores a $400 \mathrm{~m}^{2}$ y que reciben niveles de renta de suelo por debajo de los promedios de mercado (porcentaje de propietarios que estimamos alrededor de $40 \%$ ), la renta de suelo capitalizada está por debajo del valor de uso de su propiedad, lo que implica una pérdida patrimonial y también, eventualmente, una pérdida de capacidad económica de permanecer en el entorno.

En cualquier caso, un indicador tan claro como la tasa de captura de la renta (la relación dispar de ganancia por incrementos de rentas de suelo entre las inmobiliarias y los propietarios residentes) nunca llega a ser muy alta en esta zona, incluso en algunos casos, es apenas superior a uno. Es decir, la explotación del rent gap es rentable, pero no se realiza mayoritariamente en desmedro de los residentes tradicionales, ni inhabilita a la mayoría de éstos para encontrar vivienda de reemplazo al interior de la misma zona, como ocurre en otras comunas de Santiago. Nuestra conclusión es que las condiciones materiales de gentrificación (es decir, la incapacidad de residentes locales vulnerables de permanecer en un barrio que se encarece) no se dan de manera extendida y mayoritaria en el sector Irarrázaval poniente.

Sin embargo, los datos sí muestran que la lógica de crecimiento de los precios de suelo y la saturación del espacio de los barrios amenazan con ahuyentar la inversión de los agentes productores. En la medida que los precios de suelo aumentan, los mercados de renovación en los barrios se saturan, el carácter monopsónico de la demanda por suelo desaparece, y las propiedades que no fueron desarrolladas en su momento ven reducir drásticamente su valor. Aquí es cuando aparece el rol del Estado. Si bien los instrumentos facilitadores de la inversión inmobiliaria a nivel nacional son conocidos (mayormente a través de la Ley y Ordenanza General de 
Urbanismo y Construcción y las exenciones tributarias), es a nivel municipal donde aparecen sorpresas.

El municipio, aludiendo al beneficio que trae consigo el alza de los valores de suelo, puede (y lo hace) intervenir fuertemente al modificar el escenario de la zonificación local, con el objetivo de ampliar la brecha de renta y continuar reproduciendo la inversión de los agentes productores, como ocurrió en 2004 con el cambio que liberalizó la avenida Irarrázaval, y luego el 2007, con la apertura de rentas potenciales mayores hacia otras zonas de la comuna.

La renta potencial puede ser amplificada hasta niveles insospechados; los límites se encuentran en la capacidad física y funcional del espacio y la capacidad de reacción y oposición que muchas veces desarrollan asociaciones de vecinos organizados. La secuencia de modificaciones al Plan Regulador de Nuñoa, a partir de 1989, puede ser leída como un caso elocuente de esto, lo es también la dependencia a un porcentaje de esas rentas por el propio organismo municipal como base financiera para su operación. Responsablemente, se puede aducir que el municipio de Núñoa, entre 2005 y 2008, en un margen considerable, dependió financieramente de los réditos generados por la intensa explotación de mercado de renovación urbana en el sector Irarrázaval poniente.

El proceso de renovación urbana en Santiago y su apertura a comunas del pericentro de Santiago son manifestaciones político-económicas contemporáneas del modelo de desarrollo urbano adoptado y desarrollado en Chile desde mediados de la década de los setenta. Para entender estas dinámicas es preciso comprender la naturaleza orgánica -no estática- del sistema económico-político de la ciudad.

Se debe comprender, de inicio, que la producción del espacio urbano es un proceso conducido por agentes económicos y políticos que operan con procedimientos generalmente desconocidos por la sociedad y que expresan enormes disparidades de poder mediante la monopolización de los cambios radicales en la morfología y medio ambiente, a través de medios, en su mayoría institucionalizados y legales para obtener réditos considerables y recircularlos en el mercado en forma de capital o inversiones financieras.

Luego, comprender que de no mediar cambios políticos y nuevos instrumentos urbanos que aseguren un retorno y redistribución de las desiguales capturas de renta de suelo generadas en la ciudad, la intensa explotación de la renovación urbana en Chile seguirá siendo un mercado que beneficiará a unos pocos, mientras que las pérdidas patrimoniales irreversibles implicadas en esta suerte de masacre urbana seguirán afectando a la mayoría de los actores urbanos. 
Esperamos que el modelo analítico presentado en este artículo pueda ser útil para entender y, llegado el caso, controlar procesos análogos ocurridos en otras comunas o ciudades del país, e incluso del continente.

\section{Bibliografía}

Aguirre, Carlos y Daniela León (2007), "Análisis descriptivo de la evolución urbana de la comuna de Nuñoa 2001 a 2006”, Urbano, X (16), Universidad del Bío-Bío, Concepción, pp. 60-72.

Cattaneo, Rodrigo (2011), "Los fondos de inversión inmobiliaria y la producción privada de vivienda en Santiago de Chile: ¿Un nuevo paso hacia la financiarización de la ciudad?", EURE, XXXVII (112), Instituto de Estudios Urbanos y Territoriales de la Pontificia Universidad Católica de Chile, Santiago de Chile, pp. 5-22.

Clark, Eric (1988), "The rent gap and transformation of the built environment: case studies in Malmo 1860-1985", Geografiska Annaler. Series B, Human Geography, LXX (2), Swedish Society of Anthropology and Geography, Huddinge, pp. 241-254.

Clark, Eric (1995), “The rent gap re-examined”, Urban Studies, IX, Urban Studies Foundation, Glasgow, pp. 1489-1503.

Clark, Eric (2005), "The order and simplicity of gentrification - a political challenge", en Rowland Atkinson y Gary Bridge (eds.), Gentrification in a global context: the new urban colonialism, Routledge, London, pp. 256-264.

Contreras, Yasna (2011), "La recuperación urbana y residencial del centro de Santiago. Nuevos habitantes, cambios socioespaciales significativos", EURE, XXXVII (112), Instituto de Estudios Urbanos y Territoriales de la Pontificia Universidad Católica de Chile, Santiago de Chile, pp. 89-113.

Hackworth, Jason (2007), The neoliberal city: governance, ideology and development in American Urbanism, Cornell University Press, Ithaca.

Hamnett, Chris, y Drew Whitelegg (2007), "Loft conversion and gentrification in London: from industrial to postindustrial land use", 
Environment and planning A, 39 (1), Pion Ltd, London, pp. 106-124.

Harvey, David (1974), "Class-monopoly rent, finance capital and the urban revolution”, Regional Studies, 8 (3-4), Regional Studies Association-Routledge, Seaford, East Sussex, pp. 239-255.

Harvey, David (1989), "From managerialism to entrepreneurialism: the transformation in urban governance in late capitalism", Geografiska Annaler. Series B, Human Geography, LXXI (1), BlackwellSwedish Society for Anthropology and Geography, Södertörn, pp. 3-17.

Hidalgo, Rodrigo, Hugo Zunino y Lily Álvarez (2007), “El emplazamiento periférico de la vivienda social en el área metropolitana de Santiago de Chile: consecuencias socio espaciales y sugerencias para modificar los criterios actuales de localización", Scripta Nova, 11 (245), Universidad de Barcelona, Barcelona.

INE (Instituto Nacional de Estadísticas) (1992), "Censo Nacional de Población. Chile 1992", Instituto Nacional de Estadísticas, Santiago de Chile.

INE (Instituto Nacional de Estadísticas) (2002), "Censo Nacional de Población. Chile 2002”, Instituto Nacional de Estadísticas, Santiago de Chile.

Inzulza-Contardo, Jorge (2012), “'Latino-Gentrification'? Focusing on physical and socioeconomic patterns of change in Latin American inner cities", Urban Studies, IL (10), Urban Studies Journal Limited, Glasgow, pp. 2085-2107.

Janoschka, Michael y Antoine Casgrain (2011), "Urbanismo neoliberal y gentrificación en Santiago de Chile. Diálogos entre teoría urbana y reivindicación vecinal", documento de trabajo de la Corporación Educacional Poblar, Santiago de Chile, <http://penalo lenvotano.bligoo.cl/media/users/17/863351/files/167929/ MPL_Gentrificacion.pdf>, 2 febrero de 2013.

Janoschka, M., J. Sequera, J. y L. Salinas (2014), “Gentrification in Spain and Latin America - a critical dialogue", International Journal 
of Urban and Regional Research, 38 (4), Blackwell, Oxford, pp. 1234-1265.

López-Morales, Ernesto (2011), "Gentrification by ground rent dispossession. The shadows cast by large scale urban renewal in Santiago de Chile", International Journal of Urban and Regional Research, XXXV (2), Blackwell, Oxford, pp. 1-28.

López-Morales, Ernesto (2013a), Urbanismo proempresarial y destrucción creativa: un estudio de caso de la estrategia de renovación urbana en el pericentro de Santiago de Chile, 1990-2005, Infonavit-Universidad Autónoma del Estado de México, México.

López-Morales, Ernesto (2013b), Gentrificación en Chile: aportes conceptuales y evidencias para una discusión necesaria, Revista de Geografía Norte Grande, 56, Pontificia Universidad Católica, Santiago, pp. 31-52.

Mattos, Carlos de (2007), "Globalización, negocios inmobiliarios y transformación urbana”, Nueva Sociedad, 212, Fundación Friedrich Ebert, Buenos Aires, pp. 82-96.

Mattos, Carlos de (2010), "Una nueva geografía latinoamericana en el tránsito de la planificación a la gobernanza, del desarrollo al crecimiento", EURE, XXXVI (108), Instituto de Estudios Urbanos y Territoriales de la Pontificia Universidad Católica de Chile, Santiago de Chile, pp. 167-179.

Minvu (Ministerio de Vivienda y Urbanismo) (2007a), "Ley general de urbanismo y construcciones. Ministerio de Vivienda y Urbanismo", Ministerio de Vivienda y Urbanismo, Santiago.

Minvu (Ministerio de Vivienda y Urbanismo) (2007b), "Ordenanza general de urbanismo y construcciones", Ministerio de Vivienda y Urbanismo, Santiago.

Mlynarz, Danae (2007), "Participación ciudadana en el proceso de diseño y modificación de los planes reguladores comunales. Propuesta desde diversos actores", tesis de grado de magíster, Universidad de Concepción, Concepción. 
Molotch, Harvey (1993), "The political economy of growth machines", Journal of Urban Affairs, XV (1), Wiley-Blackwell, Milwaukee, pp. 29-53.

Municipalidad de Nuuñoa (2002), "Proyecto de Modificación. Plan Regulador Comunal de Nuñoa. Parte del sector Zona Z1. Av. Irarrázaval; Zona Z-2 ; Zona Z-3 y Zona Z-4", memoria, Secretaría Comunal de Planificación, Santiago de Chile.

Núnez, Claudina (2006), "Plan Regulador Comunal. Una propuesta desde la comunidad de Pedro Aguirre Cerda", documento de trabajo, Municipalidad de Pedro Aguirre Cerda, Santiago de Chile.

Peck, Jamie y Adam Tickell (2002), "Neoliberalizing space", Antipode, XXXIV (3), Wiley-Blackwell, Oxford, pp. 380-404.

Peck, Jamie y Adam Tickell (2002), "Neoliberalizing space", Antipode, xxxiv (3), Wiley-Blackwell, Oxford, pp. 380-404.

Ramos, Marcela (2011), "Es mentira y está probado que subir los impuestos hace caer la inversión”, Ciper Chile, 16 de noviembre, Fundación Centro de Investigación Periodística, Santiago de Chile, <http://ciperchile.cl/2011/11/16/\%E2\%80\%9Cesmentira-y-esta-probado-que-subir-los-impuestos-hace-caer-lainversion\%E2\%80\%9D/>, 18 febrero 2012.

Ramón, Armando de (2000), Santiago de Chile (1541-1991). Historia de una sociedad urbana, Editorial Sudamericana Chilena, Santiago de Chile.

Sandroni, Paulo Henrique (2011), "Recent experience with land value capture in São Paulo, Brazil", Land Lines, XXIII (3), Lincoln Institute of Land Policy, Cambridge, pp. 14-19.

Schlack, E. y N. Turnbull (2015), "Emerging retail gentrification in Santiago de Chile. The case of Italia-Caupolicán”, en L. Lees, H. Shin y E. López-Morales (eds.), Global gentrifications. Uneven development and displacement, Policy Press, Bristol.

Shin, Hyun Bang (2009), "Residential redevelopment and the entrepreneurial local state: the implications of Beijing's shifting emphasis 
on urban redevelopment policies, Urban Studies, XLVI (13), Urban Studies Foundation, Glasgow, pp. 2815-2840.

SII (Servicio de Impuestos Internos) (2011), "Edificación autorizada, sectores privado y público, obras nuevas, por destinos y superficie, 1990-2009”, documento de trabajo, Servicio de Impuestos Internos, Santiago de Chile. <http://www.ine.cl/canales/chile_estadistico/estadisticas_economicas/edificacion/series_estadisticas/2010_xls/anuario_edificacion_1_0.xls>, 2 de febrero de 2013.

Smith, Neil (1979), "Toward a theory of gentrification a back to the city movement by capital, not people", Journal of the American Planning Association, XLV (4), American Planning Association, Chicago, pp. 538-548.

Smith, Neil (1982), "Gentrification and uneven development", Economic Geography, LVIII (2), Wiley-Blackwell, Worcester, Massachusetts, pp. 139-155.

Smith, Neil (2002), "New globalism, new urbanism: gentrification as global urban strategy", Antipode, XXXIV (3), Wiley-Blackwell, Oxford, pp. s427-450.

Smith, Neil (2013), La nueva frontera urbana: ciudad revanchista y gentrificación, Traficantes de sueños, Madrid.

Smolka, M. (2013), Implementing value capture in Latin America: policies and tools for urban development policy focus report series, Lincoln Institute of Land Policy, Cambridge.

Trivelli, Pablo (1987-2009) Boletín de Mercado de suelo, Consultora Pablo Trivelli, Santiago de Chile.

Weber, Rachel (2002), "Extracting value from the city: neoliberalism and urban redevelopment”, Antipode, XXXIV (3), Wiley-Blackwell, Oxford, pp. 519-540.

Recibido: 15 de marzo de 2013. Reenviado: 5 de septiembre de 2013. Aceptado: 5 de diciembre de 2013. 
Ernesto López-Morales. Chileno. Es doctor en planificación urbana por el University College London. Actualmente es profesor asociado docente e investigador del Departamento de Urbanismo, Universidad de Chile. Es investigador principal de proyectos Fondecyt e IRSES-Marie Curie. Su línea de investigación actual es el análisis político-económico de los procesos de reestructuración espacial en ciudades chilenas y latinoamericanas. Entre sus últimas publicaciones destacan "Insurgency and institutionalized social participation in local-level urban planning: the case of PAC comuna, Santiago de Chile, 2003-2005”, en T. Samara, S. He y G. Chen (eds.), Right to the city in the global south: transnational urban governance and socio-spatial transformations, Routledge, Oxford, pp. 221-246 (2013); en coautoría, "Urbanismo pro-empresarial en Chile: políticas y planificación de la producción residencial en altura en el pericentro del Gran Santiago", Revista INVI, XXVIII (76), Universidad de Chile, Santiago de Chile, pp. 75-114 (2012); "Gentrification by ground rent dispossession: the shadows cast by large scale urban renewal in Santiago de Chile", International Journal of Urban and Regional Research, XXXV (2), Wiley, pp. 1-28 (2013).

Daniel Meza Corvalán. Chileno. Es arquitecto por la Universidad de Chile. Actualmente es ayudante docente e investigador del Departamento de Urbanismo, Universidad de Chile. Participa en proyectos Fondecyt e IRSES-Marie Curie. Su línea de investigación actual son los alcances sociales, políticos y económicos de los procesos de densificación urbana. Entre sus últimas publicaciones destacan: en coautoría, "Urbanismo proempresarial en Chile: políticas y planificación de la producción residencial en altura en el pericentro del Gran Santiago", Revista INVI, XXVIII (76), Universidad de Chile, Santiago de Chile, pp. 75-114 (2012). 